\title{
Chemical Ecology without Borders
}

Paulo H. G. Zarbin

Published online: 17 May 2014

(C) Springer Science+Business Media New York 2014

In the late $80 \mathrm{~s}$, I had the opportunity to join a research group in chemical ecology for the first time. As an undergraduate student in Chemistry here in Brazil, I vividly remember when my colleagues commented that our supervisor, the late and beloved Prof. Tércio Ferreira, had finally subscribed to the Journal of Chemical Ecology (JCE) and, thereafter, we all would have full access to all the content of this journal. After that, I began to read it frequently and to follow every single issue of this journal - nowadays it seems trivial, but the difficulties faced to access scientific information at that time in Brazil were immense.

The fact that always caught my attention, besides obviously the interesting and elegant publications of Wittko Francke, Kenji Mori, Jerrold Meinwald, Robert 'Milt' Silverstein, among many others, was a very low (I would even say non-existent), number of articles in the journal that were not published by researchers from countries other than the U.S., Canada, and Japan, or from European countries.

Today, over 25 years have passed, and our JCE completes its 40th anniversary. By reading now easily in the computer at my desk - the studies published there, I can see a fairly different scenario from its "teenage" years; China, India, and Brazil, for example, are among the countries with the highest number of submissions of scientific papers to the journal. Although researchers from these countries still face high rejection rates, we read quite often excellent works of various authors from these parts of the world. The current scenario

P. H. G. Zarbin $(\bowtie)$

Departamento de Química, Universidade Federal do Paraná, Curitiba, Paraná, Brazil

e-mail: pzarbin@ufpr.br shows clearly that research in chemical ecology has expanded widely, and there are no more scientific and/or regional borders that might block the continuity of such expansion. This success is due, in my view, to the organized growth that has occurred, which translates into the creation of the APACE (Asia-Pacific Association of Chemical Ecologists) and the ALAEQ (Latin American Association of Chemical Ecologists). Such associations have focussed the attention of all countries already heavily engaged in this science, beyond their regional meetings and research groups of specific countries, by strengthening scientific exchange.

The growing success of these associations resulted last year in the first joint meeting of the International Society of Chemical Ecology-ISCE and APACE (the second already scheduled for 2017). In 2016, in Brazil, we will have the first joint meeting of ISCE and ALAEQ. The Journal of Chemical Ecology has been the official journal of ISCE since that Society's inception in 1984. It became the official journal of APACE in 2012, and hopefully soon, an affiliation also can be extended to ALAEQ.

Positive changes are always welcome, and many have happened since the beginning of this still young science. It is rewarding to observe the continuous rise of young and talented researchers involved in our research area, ensuring and deepening the knowledge of chemical ecology all over the world. The entire scientific community is to be congratulated for this success. I hope and believe that our umbrella societies, ISCE, APACE, and ALAEQ, remain engaged in the search for scientific quality and regional integration, and that the JCE continues with the responsibility of spreading our scientific advances with the same brilliance and integrity for the next 40,80 years and over. 